\title{
Pharmacological Effects of EGLP-1, a Novel Analog of Glucagon-Like Peptide-1, on Carbohydrate and Lipid Metabolism
}

\author{
Huashan Gao ${ }^{\mathrm{a}, \mathrm{b}}$ Ziwei Song ${ }^{\mathrm{a}}$ Qian Zhao You Wu $^{\mathrm{a}}$ Shanshan Tang ${ }^{\mathrm{a}}$ \\ Murad Alahdal ${ }^{a} \quad$ Yumeng Shen $^{\mathrm{a}} \quad$ Yun Xing $^{\mathrm{a}} \quad$ Yi Pan $^{\mathrm{a}}$ Jing $\mathrm{Li}^{\mathrm{a}}$ \\ Yanfeng Zhang ${ }^{\mathrm{a}}$ Liang Jin ${ }^{\mathrm{a}}$
}

aState Key Laboratory of Natural Medicines, Jiangsu Key Laboratory of Drug Screening, School of life Science and Technology, China Pharmaceutical University, bSchool of Medicine, School of Chemistry and Chemical Engineering, Pingdingshan University, China

\author{
Key Words \\ EGLP-1 • NEFA • STZ-induced hyperglycemia mice $・ \mathrm{PHSL}$
}

\begin{abstract}
Background/Aims: Abnormal glucose metabolism and lipid metabolism are two key issues in Type 1 diabetes mellitus (T1DM). Insulin can control carbohydrate metabolism adequately, but cannot regulate lipid metabolism well in patients with T1DM. Glucagon-like peptide-1 receptor agonists (GLP-1RAs) have cured type 2 diabetes mellitus in clinical trials and have improved T1DM glycemic control in preclinical studies. However, previous studies have not reported whether GLP-1 can lower the serum concentration of non-esterified fatty acids (NEFAs). In this study, we examine whether GLP-1 can affect serum NEFA levels. Methods: The bioactivity of EGLP-1 (a novel GLP-1 analog) in vitro was analyzed in CG-HEK293 cells and with highperformance liquid chromatography. An intraperitoneal glucose tolerance test (IPGTT) was used to analyze the acute and sustained hypoglycemic effects of EGLP-1 in normal C57BL/6J mice. Streptozotocin-induced hyperglycemic mice were used to study the effects of EGLP-1 on blood glucose and NEFAs as well as its mechanism. Results: EGLP-1 activated GLP-1R and resisted dipeptidyl peptidase-IV digestion in vitro. Additionally, EGLP-1 had an insulinotropic action in vivo that lasted for approximately $6 \mathrm{~h}$. In Streptozotocin-induced hyperglycemic mice, EGLP-1 improved hyperglycemia, inhibited food intake, and increased $\beta$-cell area. Serum physiological indexes showed that insulin and C-peptide levels were increased, while NEFA and triacylglycerol concentrations were decreased. Western blot analysis revealed that EGLP-1 significantly reduced phosphorylated-hormone sensitive lipase (pHSL) levels in white adipose tissue. Conclusions: EGLP-1 can improve hyperglycemia by increasing islet $\beta$-cell area and improving $\beta$-cell function, possibly due to reduced NEFA content in serum by lowering $\mathrm{pHSL}$ levels.

H. Gao and Z. Song contributed equally to this work.
\end{abstract}

Liang Jin, Yanfeng Zhang and Jing $\mathrm{Li}$
School of life Science and Technology, China Pharmaceutical University

Tongjia street 24, Nanjing, Jiangsu, 210000 (China)

Tel. +86-025-83271152, Fax +86-025-83271242, E-Mail ljstemcell@cpu.edu.cn 


\section{Introduction}

Type 1 diabetes mellitus (T1DM) is caused by an absolute lack of insulin due to autoimmune destruction of pancreatic $\beta$-cells [1]. Over the past few years, considerable research has been done on both disease prevention and treatment $[2,3]$. Although great progress has been made in the management of T1DM, the mainstay of clinical treatment remains insulin injections. Insulin is a potent regulator of blood glucose and enables patients to avoid hyperglycemia and its sequelae. However, patients with T1DM also have altered metabolism that favors lipid oxidation over carbohydrate oxidation. Compared with healthy individuals, patients with T1DM have both increased lipid oxidation and increased serum levels of non-esterified fatty acids (NEFAs) [4-7]. Insulin, however, is not a powerful regulator of lipid metabolism and cannot prevent such complications.

The incretin hormone glucagon like peptide-1 (GLP-1) is released from intestinal L-cells into the circulation following the ingestion of nutrients [8, 9]. GLP-1 promotes insulin secretion, inhibits glucagon release, delays gastric emptying, and minimizes postprandial glucose excursions [10-12]. GLP-1 receptor agonists (GLP-1RAs), such as exenatide and liraglutide, have been used clinically to treat type 2 diabetes mellitus (T2DM) with a more notable improvement of controlling blood glucose than insulin alone therapy. More recently, GLP-1RAs have been included into the treatment regimen for T1DM, with benefits including a greater reduction in hemoglobin A1c, insulin dose, and risk of hypoglycemia [13]. In animal model studies, in addition to stimulating glucose-dependent insulin secretion, GLP-1 inhibits hepatic glucose production, protects the heart as an antioxidant, relieves oxidative stress in the vascular system, and affects bone metabolism [14-18].

In summary, GLP-1RAs are potential drugs for the treatment of T1DM, but it has not been reported whether GLP-1 can decrease the serum concentration of NEFAs. In this study, we suggest a mechanism through which GLP-1 affects serum NEFA content. However, due to the short half-life (2-3 min) of natural GLP-1 [19], it is difficult to study its role as a receptor agonist directly. Therefore, our laboratory previously designed a peptide GLP-1 analog, called EGLP-1, which can resist degradation by dipeptidyl peptidase-IV (DPP-IV), and we studied its hypoglycemic action as well as its effect on NEFA lipid metabolism.

\section{Materials and Methods}

Peptide synthesis

GLP-1, exendin-4, and EGLP-1 were chemically synthesized by GenScript (Nanjing, China).

\section{Biological activities in vitro}

The CG-HEK293 cell line was cultured in Dulbecco's modified Eagle's medium (DMEM) containing ( $25 \mathrm{mM}$ glucose, $10 \%$ fetal bovine serum (FBS), $100 \mu \mathrm{g} / \mathrm{mL}$ penicillin, $100 \mu \mathrm{g} / \mathrm{mL}$ streptomycin, $50 \mu \mathrm{g} / \mathrm{mL}$ G418, and $0.5 \mu \mathrm{g} / \mathrm{mL}$ puromycin), and was used to test GLP-1R activity. GLP-1R activation by EGLP- 1 was analyzed in vitro as described previously [17].

In vitro, a stability test of EGLP-1 against DPP-IV enzymolysis was carried out as described previously [17]. Briefly, GLP-1 or EGLP-1 was mixed with an isopycnic volume of recombinant human DPP-IV enzyme (R\&D Systems, Minneapolis, MN) and incubated for different times at 37 . performance liquid chromatography (HPLC) system was used to analyze the remaining concentration of GLP-1 or EGLP-1 in the samples.

\section{Culturing of 3T3-L1 adipocytes}

Mouse 3T3-L1 pre-adipocytes were obtained from the American Type Culture Collection (Manassas, VA) and cultured in DMEM supplemented with $10 \% \mathrm{FBS}, 100 \mu \mathrm{g} / \mathrm{mL}$ penicillin and $100 \mathrm{\mu g} / \mathrm{mL}$ streptomycin at $37^{\circ} \mathrm{C}$ and $5 \% \mathrm{CO}_{2}$ in a humidified incubator. A mature adipocyte induction program was used: 1) 3T3L1 pre-adipocytes were cultured in normal medium until confluency; 2) at 2 days post-confluency (day 0 ), the cells were stimulated with DMEM induction media containing $10 \% \mathrm{FBS}, 5 \mu \mathrm{M}$ dexamethasone, 0.5 
$\mu \mathrm{g} / \mathrm{mL}$ insulin, and $0.5 \mathrm{mM}$ isobutylmethylxanthine; 3 ) after 2 days (day 2), the medium was changed to differentiation medium II containing DMEM supplemented with $10 \% \mathrm{FBS}$ and $0.5 \mu \mathrm{g} / \mathrm{mL}$ insulin; and 4) at 2 days later (day 4), the medium was changed to normal medium, and the cells were fed with $10 \%$ FBS/DMEM every 2 days until day 10. Mature 3T3-L1 adipocytes were treated with phosphate-buffered saline, EGLP-1 $(10 \mu \mathrm{M})$, exendin- $4(10 \mu \mathrm{M})$, or GLP-1 $(10 \mu \mathrm{M})$ for $12 \mathrm{~h}$ for the following experiment.

\section{Animals}

C57BL/6J mice (7-8 weeks old) were obtained from the Model Animal Research Center of Nanjing University (Nanjing, China). The mice were housed in the animal facility on a $12 \mathrm{~h} \mathrm{light-dark} \mathrm{cycle} \mathrm{at} \mathrm{the}$ Pharmaceutical Animal Experiment Center. All animals were fed according to the protocols of the National Institutes of Health and permission was granted by the China Pharmaceutical University Institute Animal Care and Use Committee (Nanjing, China).

An intraperitoneal glucose tolerance test (IPGTT) was performed with $1.5 \mathrm{~g} / \mathrm{kg}$ glucose in C57BL/6J mice (8-10 weeks old). To detect the effective time of EGLP-1 in vivo, the mice were injected subcutaneously with placebo, GLP-1 (30 nmol/kg), exendin-4 (30 nmol/kg) or EGLP-1 (30 nmol/kg). The IPGTT was performed at set time points after injection.

The mice were injected intraperitoneally with streptozotocin (STZ; Sigma, St. Louis, MO; 50 mg/kg body weight) for 5 consecutive days [20,21]. Fasting blood glucose was measured with a blood glucose meter (OMRON, Kyoto, Japan). Mice with 2 consecutive blood glucose measurements greater than $11.1 \mathrm{mM}$ after the last injection of STZ were considered hyperglycemic.

Hyperglycemic model mice were divided into 4 groups as Vehicle, GLP-1, exendin-4, and EGLP-1. All groups were injected subcutaneously twice daily with placebo or $30 \mathrm{nmol} / \mathrm{kg}$ of peptides, respectively, for 5 weeks. Body weight and fasting blood glucose (fasted for $8 \mathrm{~h}$ ) were measured once a week. At the end of the dosing cycle, blood samples were collected via retro-orbital bleeding. The levels of serum NEFAs and triglycerides (TGs) were determined by specific enzyme-linked immunosorbent assay (ELISA) kits (Nanjing Institute of Research, Nanjing, China). The levels of serum insulin, glucose, adiponectin, and C-peptide were determined by ELISA kits (Nanjing Jian Cheng Institute, Nanjing, China).

\section{Pancreas morphometry}

The pancreas was processed and stained with hematoxylin and eosin. Sections were deparaffinized, rehydrated, and immunostained for insulin (dilution 1: 300; Abcam, Cambridge, UK). The sections were examined, scanned, and analyzed as described previously [22]. The $\beta$-cell area per whole pancreas was then calculated.

\section{Real-time PCR}

Mouse subcutaneous white adipose tissue from the thighs and buttocks was pulverized in liquid nitrogen and total RNA was prepared using TRIzol (Invitrogen, Carlsbad, CA). cDNA was prepared by HiScript Q RT SuperMix for qPCR (Vazyme, Nanjing, China), and real-time PCR assays were carried out with an LC480 Light Cycler (Roche, Mannheim, Germany) using specific primers for hormone-sensitive lipase (HSL), adipose triglyceride lipase (ATGL) and monoacylglycerol lipase (MGL).

\section{Western blot analysis}

Subcutaneous white adipose tissue from the thighs and buttocks was lysed, boiled and separated by $10 \%$ sodium dodecyl sulfate-polyacrylamide gel electrophoresis. Proteins were transferred to a polyvinylidene fluoride membrane (Millipore, Bedford, MA) and blocked with Western Blot Blocking Solution (Beyotime, Shanghai, China). The following primary antibodies were used: anti-phospho-HSL (Ser563) (Cell Signaling, Danvers, MA), anti-HSL (Santa, Cruz Biotechnology, Dallas, TX), and anti-GAPDH (Santa, Cruz Biotechnology, Dallas, TX). To quantify optical density, TanonImage 1.00 software (Tanon Science \& Technology, Shanghai, China) was used.

\section{Statistical analysis}

All data are expressed as the means \pm standard error of the mean and were analyzed using Student's t-test or one-way analysis of variance followed by the Student-Newman-Keuls post hoc test by SPSS software (SPSS Inc., Chicago, IL). 


\section{Results}

\section{Sequence design and bioactivity analysis of EGLP-1 in vitro}

In order to prolong the half-life of GLP-1, EGLP-1 was designed as follows: the Ala8 was replaced by Gly, and the sequence of SSGAPPPS obtained from exendin-4 was linked to the end of GLP-1 (Fig. 1a).

Subsequently, EGLP-1 was analyzed for receptor-ligand binding activity in vitro. As shown in Fig. 1b, EGLP-1 was able to activate GLP-1R in a dose-dependent manner. The EC50 of EGLP-1 was $10.46 \mathrm{mmol} / \mathrm{L}$, which was not significantly different from the positive control GLP-1.

In vitro, the stability of EGLP-1 against DPP-IV enzymolysis was evaluated by HPLC [23]. GLP-1 or EGLP-1 was incubated with DPP-IV at $37^{\circ} \mathrm{C}$ for $1-10 \mathrm{~h}$ and the proportion of remaining intact peptides was analyzed. The results showed that GLP-1 was degraded rapidly. After incubation for $1 \mathrm{~h}$, only approximately $40 \%$ of the complete peptide remained, and after $10 \mathrm{~h}$, only $6.3 \%$ of intact GLP-1 remained. However, EGLP-1 was able to resist of DPP-IV enzymolysis completely, and after $10 \mathrm{~h}$ of incubation, almost $100 \%$ of EGLP-1 remained intact (Fig. 1c).

\section{Acute and sustained hypoglycemic effect of EGLP-1 in vivo}

To investigate the dose-response relationship of EGLP-1, an IPGTT was performed following subcutaneous injection of native GLP-1 (30 nmol/kg), exendin-4 (30 nmol/ $\mathrm{kg})$, or EGLP-1 $(0.1,1,30$, or $100 \mathrm{nmol} / \mathrm{kg})$. The results revealed that blood glucose was significantly lowered in all peptide-treated groups and there was no significant difference between the groups under the same dose. Furthermore, the minimum dose of EGLP-1 for a hypoglycemic effect was $0.1 \mathrm{nmol} / \mathrm{kg}$ (Fig. 2a). These results verified that EGLP-1 had acute insulinotropic activity and the minimum effective concentration was $0.1 \mathrm{nmol} / \mathrm{kg}$.

To evaluate the effective time of EGLP-1 in vivo, an IPGTT was performed at $0,1,2,4,6$, or $8 \mathrm{~h}$ after the subcutaneous administration of a single dose $(30 \mathrm{nmol} / \mathrm{kg}$ ) of EGLP-1, GLP-1 or exendin-4 in normal C57BL/6J mice. As shown in Fig. 2b, the hypoglycemic effect of EGLP-1 was still evident at $4 \mathrm{~h}$ after administration, and this trend continued for up to $6 \mathrm{~h}$. In contrast, the hypoglycemic effect of native GLP-1 lasted for less than $1 \mathrm{~h}$, confirming that EGLP-1 could work as a GLP-1R agonist, although exendin-4 had a longer glucose-lowering action of approximately $6 \mathrm{~h}$.

Fig. 2. Acute dose-dependent glucose-lowering activity of EGLP-1 in fasted C57BL/6J mice. (a) An IPGTT was performed after the intraperitoneal administration of placebo, GLP-1, exendin-4, or EGLP-1. (b) Blood glucose levels in fasted C57BL/6J mice during an IPGTT performed at different times after the subcutaneous administration of GLP-1, exendin-4 or EGLP-1. ${ }^{*} \mathrm{p}<0.05$ and ${ }^{* * *} \mathrm{p}<0.001$, EGLP-1 group compared with the Vehicle group; $\wedge^{\wedge \wedge} \mathrm{p}<0.001$, GLP-1 group compared with the Vehicle group; ${ }^{\# \#} \mathrm{p}<0.001$, Exendin-4 group compared with the Vehicle group; ${ }^{\$} \$ \mathrm{p}<0.001$ EGLP-1 group compared with the GLP-1 group.

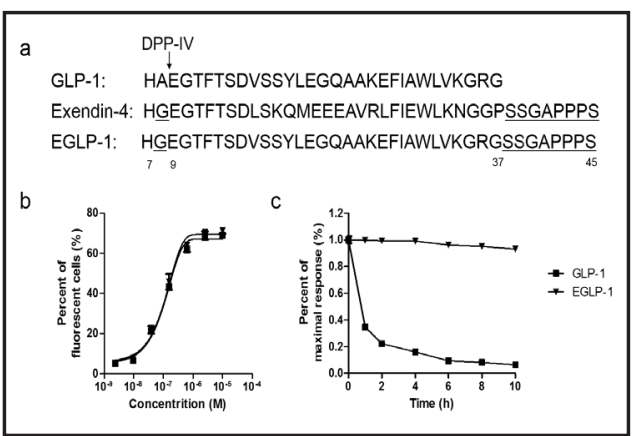

Fig. 1. Design and biological activity of EGLP-1. (a) Sequences of EGLP-1, GLP-1, and exendin-4. (b) Receptor-ligand binding activity of GLP-1 or EGLP-1 in HEK293/GLP-1R/GFP cells. (c) Stability of EGLP-1 against DPP-IV degradation in vitro.

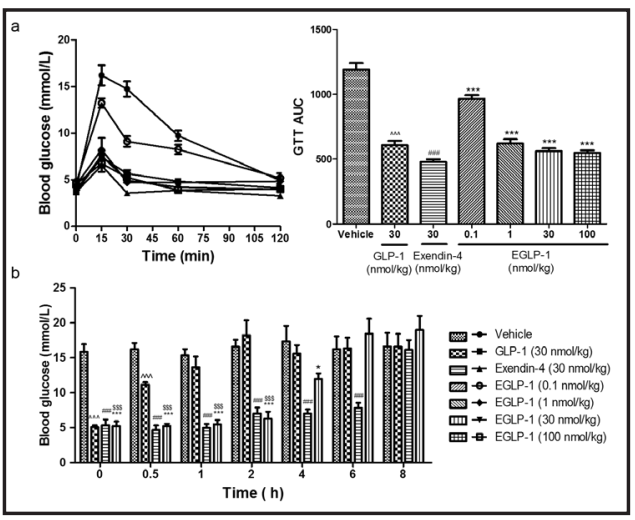




\section{Cellular Physiology Cell Physiol Biochem 2018;48:1112-1122 \begin{tabular}{l|l|l} 
DOI: 10.1159/000491978 & $\begin{array}{l}\text { O 2018 The Author(s). Published by S. Karger AG, Basel } \\
\text { www.karger.com/cpb }\end{array}$
\end{tabular} Gao et al.: EGLP1 Reduces Serum NEFA Concentrations}

Fig. 3. Chronic effect of GLP-1, EGLP-1, and exendin-4 on blood glucose, $\Delta$ body weight, cumulative food intake, and pancreas in hyperglycemic C57BL/6J mice. Weekly fasted blood glucose level (a), cumulative food intake(b), and body weight (c) during subcutaneous injection of GLP-1 (30 nmol/kg), EGLP-1 (30 nmol $/ \mathrm{kg})$, exendin-4 (30 nmol/ $\mathrm{kg}$ ) or vehicle twice daily for 5 weeks. Hematoxylin-eosin staining of the pancreas (d) of every group after 5 -week treatment. *p<0.05, ${ }^{* *} \mathrm{p}<0.01$, and ${ }^{* * *} \mathrm{p}<0.001$, EGLP-1 group compared with the Vehicle group; ${ }^{\# \#} \mathrm{p}<0.01$, and ${ }^{\# \# \#} \mathrm{p}<0.001$, Exendin-4 group compared with the Vehicle group; $\$ \$ P<0.01$, and $\$ \$ \$ P<0.001$, EGLP-1 group compared

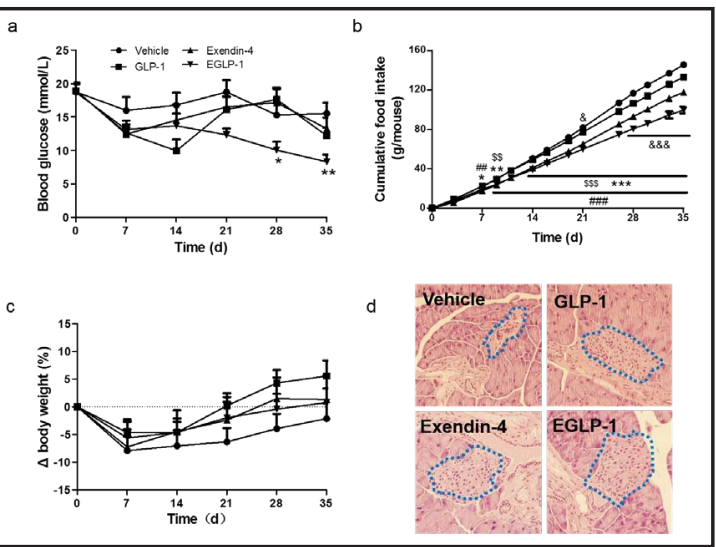
with the GLP-1 group; ${ }^{\&} \mathrm{P}<0.05$ and ${ }^{\& \& \&} \mathrm{P}<0.001$, EGLP-1 group compared with the Exendin-4 group.

Chronic activity of EGLP-1 in STZ-induced hyperglycemic mice

Following the administration of EGLP-1 to STZ-induced hyperglycemic mice, their weekly fasting blood glucose began to show a decline. After 4 weeks of EGLP-1 treatment, their fasting blood glucose was significantly different compared with placebo. At week 5, EGLP-1-treated mice had a fasting blood glucose level of only $8.31 \mathrm{mmol} / \mathrm{L}$ (compare with the Vehicle group, $\mathrm{p}<0.01$ ). As for the positive controls, that is, the GLP-1 and Exendin-4 groups, both demonstrated only a little decrease (GLP-1 group = $12.2 \mathrm{mmol} / \mathrm{L}$, Exendin-4 group $=13.3 \mathrm{mmol} / \mathrm{L}$ ) in fasting blood glucose, with no significant difference compared with the Vehicle group (Fig. 3a). Additionally, treatment with EGLP-1 reduced food intake. After 14 days, the $\mathrm{p}$ value was less than 0.001 when comparing EGLP1 treated mice with the Vehicle or GLP-1 treated group. During the 21 days of this experiment, cumulative food intake for EGLP-1 mice was $59.9 \mathrm{~g}$, and there was a significant difference between the EGLP-1 and Exendin-4 groups (Fig. 3b). Although EGLP-1 had a significant effect on food intake, it had no significant effect on body weight (Fig. 3c).

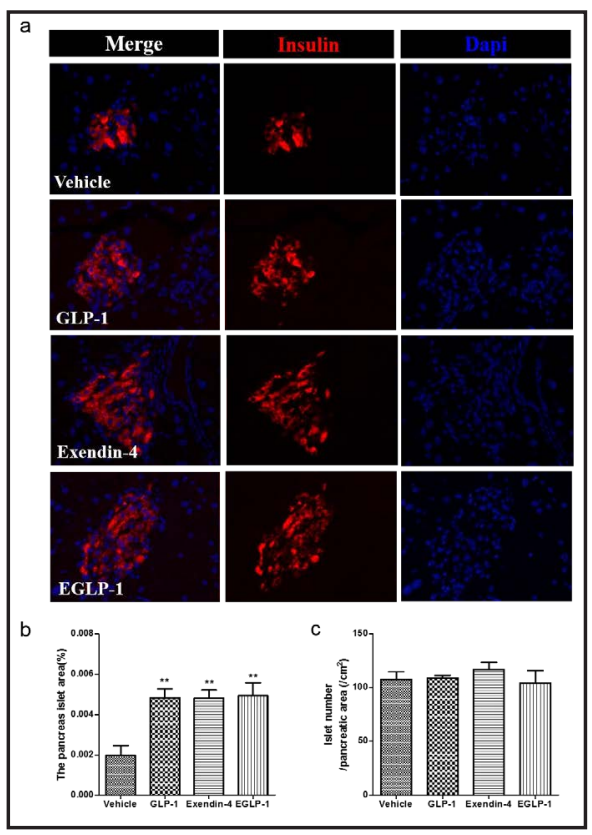

Fig. 4. Pancreatic immunoassay in hyperglycemic C57BL/6J mice after 5-week treatment. (a) Pancreatic $\beta$-cell immunostaining; (b) analysis of $\beta$-cell area in pancreas (10/10); and (c) analysis of islet number in the pancreas.

\section{EGLP-1 treatment increases $\beta$-cell area}

Hyperglycemia induced by STZ treatment is mainly caused by chemical toxicity to $\beta$-cells in pancreatic islets. GLP-1R agonists can protect pancreatic endocrine $\beta$-cells, and pancreatic islet integrity was analyzed via hematoxylin and eosin staining. The pancreatic islets of the Vehicle group were seriously damaged (Fig. 3d). However, in the EGLP-1, GLP1 , and Exendin-4 groups, pancreatic islet damage was significantly alleviated, and the islet structures appeared more intact (Fig. 3d). In order to verify whether there were larger numbers of islet $\beta$-cells, insulin immunofluorescence staining of the pancreas was performed. The pancreatic islets $\beta$-cells area of the Vehicle group was significantly decreased compared to the EGLP-1, GLP-1, and Exendin-4 groups (Fig. 4a). Islet $\beta$-cells area analysis showed that islet area was increased by 2 -fold in the GLP-1, Exendin-4, and EGLP-1 groups compared 
with the Vehicle group (Fig. 4b). There was no significant difference in the total number of islets between the groups (Fig. 4c).

Although pancreatic endocrine $\beta$-cells play an important role in blood glucose control, $\beta$-cell dysfunction is common in diabetic patients independent of the method of treatment [24]. Therefore, we assessed the concentrations of serum insulin and C-peptide, which were increased significantly after EGLP-1 treatment (compared with the Vehicle group, $\mathrm{p}<0.05$ ) (Fig. 5a, b).

\section{EGLP-1 improves physiological indexes}

Diabetic patients are known to have not only abnormal glucose metabolism, but also abnormal lipid metabolism. Thus, we observed serum TG and NEFA levels in our STZinduced hyperglycemic mice. EGLP-1 treatment significantly decreased TG and NEFA levels (TGs: EGLP-1 vs. Vehicle, $p<0.001$; NEFAs: EGLP-1 vs. Vehicle, $\mathrm{p}<0.01$ ) (Fig. 5c, d). Serum glucagon was also decreased, but not significantly (compared with the Vehicle group, $p=$ 0.1535) (Fig. 5e). Adiponectin also did not decline significantly (Fig. 5f).

EGLP-1 reduces serum NEFA level by decreasing phosphorylated-HSL ( $p H S L$ ) protein levels in adipose tissue

Adipose tissue lipolysis, as a simple and well-understood metabolic pathway, is an important source of NEFAs. During lipolysis, intracellular triacylglycerol is broken down into NEFAs and glycerol through the action of three major lipases: ATGL, HSL and MGL [25, 26]. Compared with the Vehicle group, the mRNA levels of ATGL, HSL, and MGL in adipose tissue were not changed in mice treated with EGLP-1, GLP-1, and exendin-4 (Fig. 6a-c). We examined the protein expression of key enzymes in adipose tissue to analyze the effect of EGLP-1 on lipolysis. The protein level of HSL in adipose tissue was not changed in mice treated with EGLP-1 compared to those treated with vehicle. However, pHSL, the main active form of HSL, decreased by approximately 5 -fold in adipose tissue of mice receiving EGLP-1 (Fig. 6d, e).

Fig. 5. Physiological indexes in hyperglycemic C57BL/6J mice after 5-week treatment. Concentration of serum insulin (a), C-peptide (b), TGs (c), NEFAs (d), glucagon (e), and adiponectin (f) after 5 -week treatment. ${ }^{* *} \mathrm{p}<0.01$, and ${ }^{* * *} \mathrm{p}<0.001$, EGLP-1 group compared with the Vehicle group; $\# \# \mathrm{p}<0.01$, Exendin-4 group compared with the Vehicle group; ${ }^{\$} \mathrm{p}<0.05$ and ${ }^{\$ \$} \mathrm{p}<0.001$, EGLP-1 group compared with the GLP-1 group.

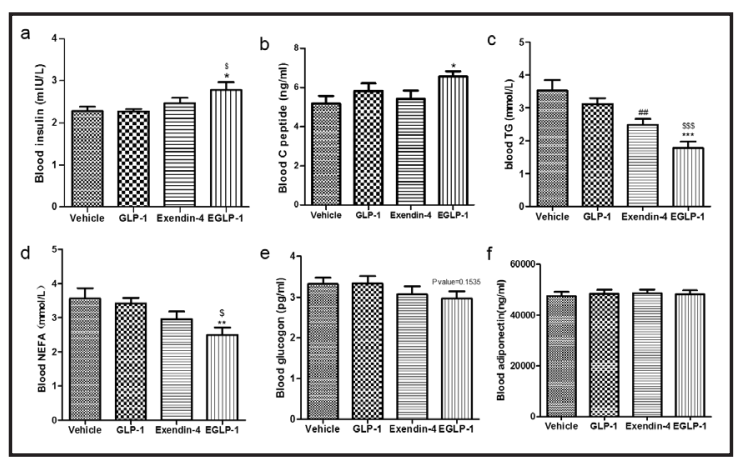

Fig. 6. Analysis of key enzymes in adipose tissue lipolysis. Quantitative real-time PCR measurement of the mRNA levels ( $n=6$ mice per group) of (a) HSL, (b) ATGL, and (c) MGL. (d) Expression of HSL and pHSL, and (e) quantification of the western blots ( $\mathrm{n}=3$ mice per group). ${ }^{* * *} \mathrm{p}<0.001$, EGLP-1 group compared with the Vehicle group; $\# \#$ $<<0.001$, Exendin-4 compared with the Vehicle group; ${ }^{\&} \mathrm{p}<0.001, \mathrm{EGLP}-1$ group compared with the Exendin-4 group; ${ }^{\wedge \wedge} \mathrm{p}<<0.001$, GLP-1 group compared with the Vehicle group.

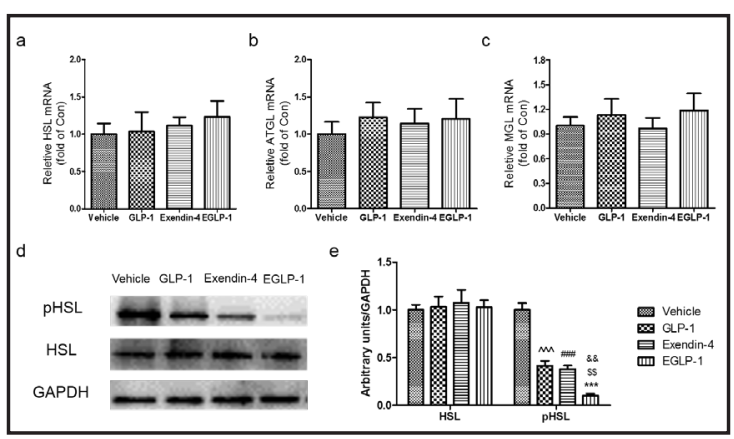


Fig. 7. Analysis of key enzymes in mature 3T3-L1 adipocytes. (a) Expression of HSL and pHSL, and (b) quantification of the western blots $(\mathrm{n}=3) .{ }^{* * *} \mathrm{p}<0.001$, EGLP-1 group compared with the Vehicle group; ${ }^{\wedge} \wedge \mathrm{p}<0.01$, GLP-1 group compared with the Vehicle group.

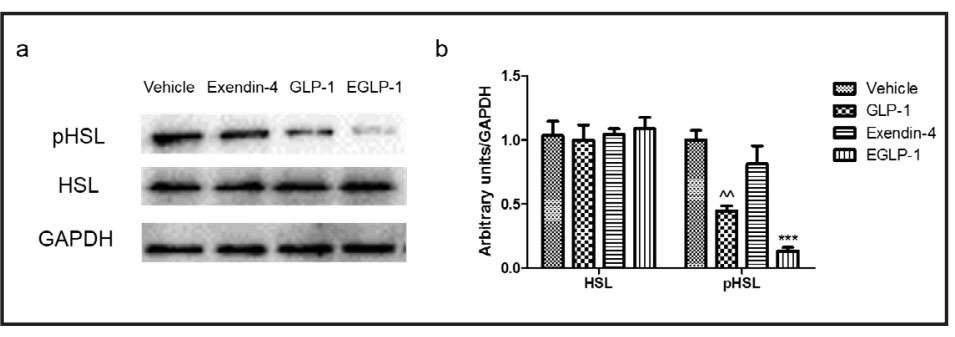

EGLP-1 reduces $p H S L$ protein levels in mature 3T3-L1 adipocytes

Similar findings of decreased adipose tissue lipolysis were observed in mature 3T3L1 adipocytes. Mature 3T3-L1 adipocytes were incubated with phosphate-buffered saline, exendin-4 $(10 \mu \mathrm{M})$, EGLP-1 $(10 \mu \mathrm{M})$, or GLP-1 $(10 \mu \mathrm{M})$ for $12 \mathrm{~h}$. EGLP-1 and GLP-1 treatment significantly decreased the level of pHSL, but exendin-4 did not. EGLP-1, GLP-1 and exendin-4 did not changed the protein level of HSL (Fig. 7a, b).

\section{Discussion}

GLP-1 exerts a large number of antidiabetic actions, of which the induction of glucosedependent insulin secretion is best known [9]. Both GLP-1 agonists and inhibitors of the enzyme DPP- IV are approved for the treatment of T2DM [27, 28]. It has been reported that GLP-1 can improve T1DM by lowering the insulin dose, hemoglobin A1c, and risk of hypoglycemia [29-31]. Carbohydrate metabolism and lipid metabolic disorders are two key features of T1DM and T2DM. Especially in T1DM patients, lipid oxidation is greatly increased, and NEFAs are higher than in normal subjects [7]. In this report, our laboratory discovered that EGLP-1, as a long-acting analog of GLP-1, could lower hyperglycemia and reduced the concentrations of NEFAs and TGs in STZ-induced hyperglycemic mice.

To obtain a long-acting analog of GLP-1, the sequence of SSGAPPPS obtained from the tail of exendin- 4 was linked to the end of GLP-1, which was designated as EGLP-1. In vitro, receptor-ligand binding activity showed that EGLP-1 could activate GLP-1R and had a similar affinity with GLP-1 (Fig. 1b). Consistent with receptor-ligand binding activity in vitro, similar to native GLP-1, EGLP-1 promoted insulin secretion in vivo with a minimum effective concentration of $0.1 \mathrm{~nm} / \mathrm{kg}$ (Fig. 2a). In vitro, HPLC revealed that EGLP-1 almost completely resisted digestion by DPP- IV. When EGLP-1 was incubated with DPP- IV for up to $10 \mathrm{~h}$, less than $10 \%$ of EGLP-1 was degraded. Comparatively, only $6.3 \%$ of GLP-1 remained intact after DPP-IV digestion (Fig. 1c). In vivo, an IPGTT revealed that a single injection of EGLP-1 could reduce blood glucose for about $6 \mathrm{~h}$ (Fig. 1c). This is consistent with the report of Finan et al., who also added the tail of exendin- 4 to a peptide triagonist, and the resultant compound had a half-life of about $5 \mathrm{~h}$ in normal C57BL/6J mice [32]. However, the effective time of EGLP-1 was less than that of exendin-4, probably because the structure of GLP-1 is different from that of exendin-4. In the following study, we improved the half-life of EGLP-1 by changing its dosage in vivo.

To verify the effectiveness of EGLP-1 in vivo, we administered EGLP-1, GLP-1, exendin-4, or vehicle to STZ-treated hyperglycemic mice. After 5 weeks of treatment, EGLP-1 clearly ameliorated the hyperglycemia (compared with the Vehicle group, $\mathrm{p}<0.01$ ). However, neither GLP-1 nor exendin-4 demonstrated any improvement compared with vehicle (Fig. $3 a)$. Consistent with the report that GLP-1R agonist was able to inhibit food intake through central regulation [33-35], EGLP-1 significantly inhibited food intake, and it even had a comparatively better effect than exendin 4 from the third week onward (Fig. 3b). This indicated that EGLP-1 can act as an effective GLP-1R agonist.

Both EGLP-1 and exendin-4 are long-lasting GLP-1R agonists, but they have different hyperglycemic effects. Why? It is well known that pancreatic endocrine $\beta$-cells play a central role in glucose metabolism, so we analyzed pancreata by hematoxylin and eosin 
staining, which revealed that the pancreas of the Vehicle group was seriously damaged. In comparison, EGLP-1, GLP-1, and exendin-4 treatment preserved islet integrity. This indicated that these GLP-1R agonists had a protective effect on islet morphology, which is consistent with our previous report [17]. It has also been reported that GLP- 1 can increase $\beta$-cell mass by stimulating $\beta$-cell proliferation and inhibiting apoptosis [36, 37]. Islet immunostaining for insulin showed that EGLP-1, GLP-1 and exendin-4 treatment significantly increased the $\beta$-cell area compared with the Vehicle group (Fig. 4), but there was no significant difference between EGLP-1, GLP-1 and exendin-4 treatment. In order to detect whether the $\beta$-cells were able to secrete insulin, we detected serum insulin and C-peptide levels. The results showed that EGLP-1 treatment significantly increased insulin and C-peptide levels (Fig. 5a, b). These results indicated that EGLP-1 reduced blood glucose by improving the function of $\beta$-cells.

It has been reported that GLP-1 possesses a number of anti-diabetic actions, including glucose-dependent insulin secretion (insulinotropic action) dependent on GLP-1R [9] and an insulin-like (insulinomimetic) action independent on GLP-1R [38-41] in addition to its insulinotropic action. This suggests that EGLP-1 may have a new role in improving $\beta$-cell function independently of GLP-1R. Exendin-4, a GLP-1R agonist, lacks insulinomimetic action, while GLP-1 has insulinomimetic action, but its half-life is only 2-3 min [19]. EGLP-1 is not only a long-acting GLP-1R agonist, but also retains the structure of GLP-1, so it may have possess of their abilities to increase C-peptide and insulin levels.

It has been reported that elevated levels of NEFAs contribute to the impaired responsiveness to GLP-1, partially through the down-regulation of GLP-1 receptor signaling. Improvements in lipid control in mouse models of obesity and diabetes increase the efficacy of incretin-based therapies [42]. It is recognized that NEFAs have stimulatory and detrimental effects on pancreatic $\beta$-cells. The acute exposure of pancreatic $\beta$-cells to saturated NEFAs results in a substantial increase in insulin release, whereas chronic exposure results in desensitization and suppressed secretion, which then induces apoptosis $[43,44]$. In addition, the STZ-induced hyperglycemic mouse model has the features of dyslipidemia, increased $\beta$-oxidation, and elevated levels of TGs and NEFAs [7, 17, 45]. Therefore, we measured NEFA concentration in our experimental groups. The results showed that the concentration of NEFAs was significantly decreased in the EGLP-1 group (Fig. 5d), suggesting that EGLP-1 may improve $\beta$-cell function by decreasing serum NEFA levels. In order to further study the mechanism by which EGLP-1 reduces NEFAs, we detected the expression of HSL, a key enzyme of lipid metabolism, and pHSL, which is the main active form of HSL [25]. Western blotting analysis showed that EGLP-1 significantly reduced pHSL levels (Fig. 6). In studies of mature 3T3-L1 adipocytes, we obtained similar findings in that EGLP-1 significantly decreased pHSL levels. This indicated that EGLP-1 reduced serum NEFA levels by reducing pHSL levels, which may improve the function of $\beta$-cells.

Overall, the results of this study suggest that EGLP-1 can reduce hyperglycemia and lower the concentration of serum NEFAs. In vivo and in vitro, biological activity analyses confirmed that EGLP-1 is a long-acting GLP-1R agonist that exerts an insulin-secretion function. In an STZ-induced hyperglycemic mouse model, EGLP-1 increased $\beta$-cell mass in islets and improved $\beta$-cell function, possibly by reducing serum NEFA levels. In addition, EGLP-1 reduced serum NEFA levels by reducing the levels of pHSL. Therefore, EGLP-1 can be used as an adjuvant therapy to insulin to improve glycemic control and lipid metabolism in patients with T1DM.

\section{Abbreviations}

GLP-1 (glucagon-like peptide-1); EGLP-1 (a novel GLP-1 analogue); GLP-1R (glucagonlike peptide-1 receptor); STZ (streptozotocin; ); DPP-IV (dipeptidyl peptidase IV); CGHEK293 (co-transfected with HuGLP-1R and CRE plasmid in human embryonic kidney 293); IPGTT (intraperitoneal glucose tolerance test); TAG (Triglycerides); HSL (hormone sensitive lipase gene). 


\section{Cellular Physiology Cell Physiol Biochem 2018;48:1112-1122 and Biochemistry Published $\begin{aligned} & \text { DOI: 10.1159/000491978 } \\ & \text { (c) } 2018 \text { The Author(s). Published by S. Karger AG, Basel } \\ & \text { www.karger.com/cpb }\end{aligned}$}

Gao et al.: EGLP1 Reduces Serum NEFA Concentrations

\section{Acknowledgements}

This work was supported by National High Technology Research and Development Program of China (863 Program, No.2015AA020314); Supported by National Natural Science Foundation of China (Grant No. 81570696 and No. 31270985); Supported by Excellent Youth Foundation of Jiangsu Scientific Committee (BK20140029); Supported by sponsored by Qing Lan Project; Supported by Program for Jiangsu Province Innovative Research Team; Priority Academic Program Development of Jiangsu Higher Education Institutions, Top-notch Academic Programs Project of Jiangsu Higher Education Institutions (PPZY2015A057); the Fundamental Research Funds for the Central Universities (2016ZPY010, 2632017PY06); Pingdingshan High-level Talent Startup Fund (PXY-BSQD-2018011).

L.J. designed and conducted the experiments. H.G. performed all the experiments and prepared the figures. Z.S., Q.Z., Y.W., S.T., Y.S., Y.X., Y.P. \& Y.Z. helped with the animal experiments and collected the sample data. M.A. reorganized and reviewed the manuscripts. All authors contributed to the writing of the manuscript and discussed the research in the experimental period.

\section{Disclosure Statement}

The authors declare to have no competing financial interests.

\section{References}

$\rightarrow 1$ Devendra D, Liu E, Eisenbarth GS: Type 1 diabetes: recent developments. BMJ 2004;328:750-754.

2 Beauchamp G, Haller MJ: Can we prevent type 1 diabetes? Curr Diab Rep 2015;15:86.

-3 Simmons KM, Gottlieb PA, Michels AW: Immune Intervention and Preservation of Pancreatic Beta Cell Function in Type 1 Diabetes. Curr Diab Rep 2016;16:97.

4 Wohl P, Wohl P, Girman P, Pelikanova T: Inflexibility of energy substrate oxidation in type 1 diabetic patients. Metabolism 2004;53:655-659.

5 Tuominen JA, Ebeling P, Vuorinen-Markkola H, Koivisto VA: Post-marathon paradox in IDDM: unchanged insulin sensitivity in spite of glycogen depletion. Diabet Med 1997;14:301-308.

6 Raguso CA, Coggan AR, Gastaldelli A, Sidossis LS, Bastyr EJ, 3rd, Wolfe RR: Lipid and carbohydrate metabolism in IDDM during moderate and intense exercise. Diabetes 1995;44:1066-1074.

7 Perseghin G, Lattuada G, De Cobelli F, Esposito A, Costantino F, Canu T, Scifo P, De Taddeo F, Maffi P, Secchi A, Del Maschio A, Luzi L: Reduced intrahepatic fat content is associated with increased whole-body lipid oxidation in patients with type 1 diabetes. Diabetologia 2005;48:2615-2621.

8 Baggio LL, Drucker DJ: Biology of incretins: GLP-1 and GIP. Gastroenterology 2007;132:2131-2157.

- Kieffer TJ, Habener JF: The glucagon-like peptides. Endocr Rev 1999;20:876-913.

$>10$ Nauck MA, Heimesaat MM, Behle K, Holst JJ, Nauck MS, Ritzel R, Hufner M, Schmiegel WH: Effects of glucagon-like peptide 1 on counterregulatory hormone responses, cognitive functions, and insulin secretion during hyperinsulinemic, stepped hypoglycemic clamp experiments in healthy volunteers. J Clin Endocrinol Metab 2002;87:1239-1246.

11 Nauck MA, Niedereichholz U, Ettler R, Holst JJ, Orskov C, Ritzel R, Schmiegel WH: Glucagon-like peptide 1 inhibition of gastric emptying outweighs its insulinotropic effects in healthy humans. Am J Physiol 1997;273:E981-988.

12 Guo H, Li H, Wang B, Ding W, Ling L, Yang M, Gu Y, Niu J: Protective Effects of Glucagon-Like Peptide-1 Analog on Renal Tubular Injury in Mice on High-Fat Diet. Cell Physiol Biochem 2017;41:1113-1124.

13 Harris KB, Boland CL: Adjunctive Role of Glucagon-Like Peptide-1 Receptor Agonists in the Management of Type 1 Diabetes Mellitus. Pharmacotherapy 2016;36:1011-1020.

14 Tomas E, Habener JF: Insulin-like actions of glucagon-like peptide-1: a dual receptor hypothesis. Trends Endocrinol Metab 2010;21:59-67. 
15 Davidson MH: Cardiovascular effects of glucagonlike peptide-1 agonists. Am J Cardiol 2011;108:33B-41B.

16 Ceccarelli E, Guarino EG, Merlotti D, Patti A, Gennari L, Nuti R, Dotta F: Beyond glycemic control in diabetes mellitus: effects of incretin-based therapies on bone metabolism. Front Endocrinol (Lausanne) 2013;4:73.

17 Gao HS, Zhao Q, Song ZW, Yang ZC, Wu Y, Tang SS, Alahdal M, Zhang YF, Jin L: PGLP-1, a novel long-acting dual-function GLP-1 analog, ameliorates streptozotocin-induced hyperglycemia and inhibits body weight loss. FASEB J 2017;31:3527-3539.

18 Jiang YQ, Chang GL, Wang Y, Zhang DY, Cao L, Liu J: Geniposide Prevents Hypoxia/Reoxygenation-Induced Apoptosis in H9c2 Cells: Improvement of Mitochondrial Dysfunction and Activation of GLP-1R and the PI3K/AKT Signaling Pathway. Cell Physiol Biochem 2016;39:407-421.

19 Deacon CF, Nauck MA, Toft-Nielsen M, Pridal L, Willms B, Holst JJ: Both subcutaneously and intravenously administered glucagon-like peptide I are rapidly degraded from the NH2-terminus in type II diabetic patients and in healthy subjects. Diabetes 1995;44:1126-1131.

20 Rossini AA, Williams RM, Appel MC, Like AA: Sex differences in the multiple-dose streptozotocin model of diabetes. Endocrinology 1978;103:1518-1520.

21 Like AA, Rossini AA: Streptozotocin-induced pancreatic insulitis: new model of diabetes mellitus. Science 1976;193:415-417.

-22 Cai EP, Casimir M, Schroer SA, Luk CT, Shi SY, Choi D, Dai XQ, Hajmrle C, Spigelman AF, Zhu D, Gaisano HY, MacDonald PE, Woo M: In vivo role of focal adhesion kinase in regulating pancreatic beta-cell mass and function through insulin signaling, actin dynamics, and granule trafficking. Diabetes 2012;61:1708-1718.

23 O'Harte FP, Mooney MH, Lawlor A, Flatt PR: N-terminally modified glucagon-like peptide-1(7-36) amide exhibits resistance to enzymatic degradation while maintaining its antihyperglycaemic activity in vivo. Biochim Biophys Acta 2000;1474:13-22.

24 Turner RC, Cull CA, Frighi V, Holman RR: Glycemic control with diet, sulfonylurea, metformin, or insulin in patients with type 2 diabetes mellitus: progressive requirement for multiple therapies (UKPDS 49). UK Prospective Diabetes Study (UKPDS) Group. JAMA 1999;281:2005-2012.

25 Lafontan M, Langin D: Lipolysis and lipid mobilization in human adipose tissue. Prog Lipid Res 2009;48:275-297.

26 Chen J, Zhao H, Ma X, Zhang Y, Lu S, Wang Y, Zong C, Qin D, Wang Y, Yingfeng Yang Y, Wang X, Liu Y: GLP1/GLP-1R Signaling in Regulation of Adipocyte Differentiation and Lipogenesis. Cell Physiol Biochem 2017;42:1165-1176.

27 Russell S: Incretin-based therapies for type 2 diabetes mellitus: a review of direct comparisons of efficacy, safety and patient satisfaction. Int J Clin Pharm 2013;35:159-172.

28 Urquhart BS: Comparing incretin-based therapies. Evaluating GLP-1 agonists and DPP-4 inhibitors for type 2 diabetes mellitus. Adv NPs PAs 2010;1:38-44.

29 Pettus J, Hirsch I, Edelman S: GLP-1 agonists in type 1 diabetes. Clin Immunol 2013;149:317-323.

-30 Kielgast U, Holst JJ, Madsbad S: Treatment of type 1 diabetic patients with glucagon-like peptide-1 (GLP-1) and GLP-1R agonists. Curr Diabetes Rev 2009;5:266-275.

-31 Kielgast U, Holst JJ, Madsbad S: Antidiabetic actions of endogenous and exogenous GLP-1 in type 1 diabetic patients with and without residual beta-cell function. Diabetes 2011;60:1599-1607.

-32 Finan B, Yang B, Ottaway N, Smiley DL, Ma T, Clemmensen C, Chabenne J, Zhang L, Habegger KM, Fischer K, Campbell JE, Sandoval D, Seeley RJ, Bleicher K, Uhles S, Riboulet W, Funk J, Hertel C, Belli S, Sebokova E, Conde-Knape K, Konkar A, Drucker DJ, Gelfanov V, Pfluger PT, Muller TD, Perez-Tilve D, DiMarchi RD, Tschop MH: A rationally designed monomeric peptide triagonist corrects obesity and diabetes in rodents. Nat Med 2015;21:27-36.

33 Turton MD, O’Shea D, Gunn I, Beak SA, Edwards CM, Meeran K, Choi SJ, Taylor GM, Heath MM, Lambert PD, Wilding JP, Smith DM, Ghatei MA, Herbert J, Bloom SR: A role for glucagon-like peptide-1 in the central regulation of feeding. Nature 1996;379:69-72.

34 Meeran K, O’Shea D, Edwards CM, Turton MD, Heath MM, Gunn I, Abusnana S, Rossi M, Small CJ, Goldstone AP, Taylor GM, Sunter D, Steere J, Choi SJ, Ghatei MA, Bloom SR: Repeated intracerebroventricular administration of glucagon-like peptide-1-(7-36) amide or exendin-(9-39) alters body weight in the rat. Endocrinology 1999;140:244-250.

-35 Szayna M, Doyle ME, Betkey JA, Holloway HW, Spencer RG, Greig NH, Egan JM: Exendin-4 decelerates food intake, weight gain, and fat deposition in Zucker rats. Endocrinology 2000;141:1936-1941. 


\section{Cellular Physiology Cell Physiol Biochem 2018;48:1112-1122 \begin{tabular}{l|l} 
DOI: 10.1159/000491978 & $\begin{array}{l}\text { O 2018 The Author(s). Published by S. Karger AG, Basel } \\
\text { www.karger.com/cpb }\end{array}$
\end{tabular}}

Gao et al.: EGLP1 Reduces Serum NEFA Concentrations

-36 Farilla L, Hui H, Bertolotto C, Kang E, Bulotta A, Di Mario U, Perfetti R: Glucagon-like peptide-1 promotes islet cell growth and inhibits apoptosis in Zucker diabetic rats. Endocrinology 2002;143:4397-4408.

-37 Drucker DJ: Glucagon-like peptide-1 and the islet beta-cell: augmentation of cell proliferation and inhibition of apoptosis. Endocrinology 2003;144:5145-5148.

-38 Tomas E, Stanojevic V, Habener JF: GLP-1 (9-36) amide metabolite suppression of glucose production in isolated mouse hepatocytes. Horm Metab Res 2010;42:657-662.

-39 Tomas E, Wood JA, Stanojevic V, Habener JF: Glucagon-like peptide-1(9-36)amide metabolite inhibits weight gain and attenuates diabetes and hepatic steatosis in diet-induced obese mice. Diabetes Obes Metab 2011;13:26-33.

40 Ban K, Noyan-Ashraf MH, Hoefer J, Bolz SS, Drucker DJ, Husain M: Cardioprotective and vasodilatory actions of glucagon-like peptide 1 receptor are mediated through both glucagon-like peptide 1 receptordependent and -independent pathways. Circulation 2008;117:2340-2350.

41 Sonne DP, Engstrom T, Treiman M: Protective effects of GLP-1 analogues exendin-4 and GLP-1(9-36) amide against ischemia-reperfusion injury in rat heart. Regul Pept 2008;146:243-249.

42 Kang ZF, Deng Y, Zhou Y, Fan RR, Chan JC, Laybutt DR, Luzuriaga J, Xu G: Pharmacological reduction of NEFA restores the efficacy of incretin-based therapies through GLP-1 receptor signalling in the beta cell in mouse models of diabetes. Diabetologia 2013;56:423-433.

43 Haber EP, Ximenes HM, Procopio J, Carvalho CR, Curi R, Carpinelli AR: Pleiotropic effects of fatty acids on pancreatic beta-cells. J Cell Physiol 2003;194:1-12.

44 Newsholme P, Keane D, Welters HJ, Morgan NG: Life and death decisions of the pancreatic beta-cell: the role of fatty acids. Clin Sci (Lond) 2007;112:27-42.

45 Franko A, Huypens P, Neschen S, Irmler M, Rozman J, Rathkolb B, Neff F, Prehn C, Dubois G, Baumann M, Massinger R, Gradinger D, Przemeck GK, Repp B, Aichler M, Feuchtinger A, Schommers P, Stohr O, SanchezLasheras C, Adamski J, Peter A, Prokisch H, Beckers J, Walch AK, Fuchs H, Wolf E, Schubert M, Wiesner RJ, Hrabe de Angelis M: Bezafibrate Improves Insulin Sensitivity and Metabolic Flexibility in STZ-Induced Diabetic Mice. Diabetes 2016;65:2540-2552. 